\title{
Experiencia en la mnemotecnia y aprendizaje incidental con imágenes normales y raras
}

\author{
Mnemotechnic experience and incidental learning \\ with normal and bizarre imagery
}

\author{
Alfredo CAMPOS \\ Rocío GÓMEZ-JUNCAL ${ }^{2}$ \\ María José PÉREZ-FABELLO2
}

\begin{abstract}
Resumen
En nuestra investigación deseábamos saber si la experiencia en la utilización de imágenes mentales y el tipo de imagen utilizada: sin imagen, imagen normal, imagen rara, e imagen mixta, influía en el recuerdo inmediato, al cabo de un día y de una semana. Para ello seleccionamos a 198 sujetos, con una media de edad de 14.4 años, y los distribuimos, al azar en cuatro grupos: el grupo que no utilizó imágenes mentales, el que utilizó imágenes normales, el que utilizó imágenes raras, y el grupo mixto. A los grupos se les presentaron 16 oraciones, cada una con tres palabras en mayúsculas. Los sujetos tenían que puntuar la relación entre las tres palabras (el grupo sin imagen), o la viveza suscitada por cada oración (grupos con imagen). Posteriormente se midió el recuerdo, el reconocimiento, el falso reconocimiento, el acceso a la oración, los ítems por oración recordados, y el número de oraciones totalmente recordadas. También se preguntó a los sujetos por su experiencia en la utilización de imágenes. Encontramos que la experiencia en la utilización de imágenes influyó al cabo de un día y de una semana en el recuerdo, en el reconocimiento, en el número de oraciones totalmente recordadas, y en el acceso a la oración. Los grupos que utilizaron imágenes raras e imágenes mixtas manifestaron, después de una semana, mayor rendimiento en todas las variables dependientes (excepto en ítems por sentencia recordados), que los grupos que utilizaron imágenes normales o no utilizaron imágenes mentales.
\end{abstract}

Unitermos: Imagen. Memoria. Procesos cognitivos.

\begin{abstract}
This study sought to evaluate the effects of the use of imagery in immediate recollection, at the end of one day and at the end of the week, according to the type of imagery employed: no images, normal image, unusual image and mixed image. For this test, 198 subjects were selected with an average age of 14.4 years, randomly assigned to one of four experimental groups: 1) group with no mental images, 2) group which used normal mental images, 3) group which used unusual images and 4) mixed group. A set of 16 sentences was shown to the groups, each of which contained three words written in block capitals. The subjects had to indicate the relationship between the three words (in the group without any image), or the intensity of the image provoked by each sentence (groups with images). We subsequently conducted an evaluation of the recollection, recognition, false recognition, access to the sentence, the items recalled by sentence and the number of
\end{abstract}

\footnotetext{
$\nabla \nabla \nabla \nabla$

1 Universidad de Santiago de Compostela, Departamento de Psicología Básica. 15782 Santiago de Compostela. España. Correspondencia a/Correspondência para: A. CAMPOS. E-mail: <pscampos@usc.es>.

2 Universidad de Vigo, Facultad de Bellas Artes, Departamento de Análisis e Intervención Psicosocioeducativa. Pontevedra, España.
} 
sentences completely recollected. The subjects were also questioned about their experiences in the use of the images. It was ascertained that the experience in the use of the images influenced, at the end of the day and of the week, the recollection, recognition, the number of sentences completely recalled and the access to the sentence. After a week, the groups which were shown unusual or mixed images demonstrated better results in all the dependent variables (with the exception of the items recollected by sentence) than the groups which were shown normal mental images, or no images at all.

Uniterms: Image. Memory. Cognitive processes.

Son muchos los autores, desde la antigüedad hasta nuestros días, que hablan de la importancia del entrenamiento en imágenes mentales para conseguir unas imágenes más vivas como herramienta para incrementar el aprendizaje (Katz, 1983; Paivio, 1986; A. A. Sheikh \& K. S. Sheikh, 1985; A. A. Sheikh, K. S. Sheikh \& Molesky, 2002). La utilización de imágenes mentales es una habilidad aprendida que puede incrementarse mediante instrucción, adiestramiento y práctica.

Las imágenes mentales juegan un papel importante en muchas tareas cognitivas, como la memoria, el razonamiento, o la solución de problemas (Campos, González \& Amor, 2004; Denis, 1991; Higbee, 1993; Hampson, Marks \& Richardson, 1990). Se ha comprobado que el uso de las imágenes mentales mejora el aprendizaje. Se han efectuado muchos estudios dirigidos a aclarar bajo qué condiciones concretas existe tal efecto facilitador de la imagen, y cómo tiene que ser la imagen para que sea eficaz (Mercer, 1996; Worthen, 2006).

Los autores (Higbee, 1993, A. A. Sheikh \& K. S. Sheikh, 1985) recomiendan la utilización de imágenes raras para el aprendizaje, sin embargo, los estudios experimentales no muestran resultados claros. La efectividad de las imágenes raras depende de variables como el tipo de lista que se utiliza (lista pura o mixta), el momento del recuerdo (inmediato y retardado), o la forma de medir la información (recuerdo o reconocimiento).

Cuando se utilizan listas puras como material para aprender, no se encuentra el efecto beneficioso de las imágenes raras. Collyer, Jonides y Bevan (1972) y $\longrightarrow$ McDaniel, DeLosh y Merritt (2000) encontraron mayor recuerdo con imágenes normales que con imágenes raras. Otros autores (Cox \& Wollen, 1981; McDaniel \& Einstein, 1986; Wollen \& Cox, 1981) no encontraron diferencias en recuerdo entre las imágenes normales puras y las imágenes raras puras. Sin embargo, con listas mixtas, las imágenes raras son más efectivas, a corto plazo, que las imágenes normales, sobre todo si la tarea consiste en un recuerdo libre (Imai \& Richman, 1991; Marchal \& Nicolas, 2000; McDaniel et al., 2000; Tess, Hutchinson, Treloar \& Jenkins, 1999; Worthen \& Loveland, 2000-2001). Estos autores, cuando utilizaron las listas mixtas, compararon las imágenes normales con las raras de la misma lista.

A largo plazo, los resultados dependieron bastante de la demora de la prueba de recuerdo. Andreoff y Yarmey (1976) encontraron que las imágenes extrañas eran más efectivas en el aprendizaje incidental de pares asociados tras un intervalo de retención de un día. En la misma línea están los resultados de O'Brien y Wolford (1982) con intervalos de entre 5 y 7 días, y los de laccino, Dvorak y Coler (1989), Merry y Graham (1978) y Marshall, Nau y Chandler (1980) con intervalos de 7 días. Merry (1980) con intervalos de 7 a 14 días. Sharpe y Markham (1992) obtuvieron efecto de lo extraño, tanto en medidas a corto plazo, como a largo plazo. Sin embargo, Kroll, Schepeler y Angin (1986) no encontraron diferencias entre las oraciones raras y normales tras 7 días de retención, ni Poon y Walsh-Sweeney (1981) con intervalos de 1 día, 1 semana y 1 mes. Zoler, Workman y Kroll (1989) tampoco encontraron un efecto de extrañeza con listas mixtas, ni con listas puras, tras 2 días de retención.

El efecto beneficioso de lo extraño no se ha encontrado, en general, en las tareas de aprendizaje mediante listas puras (raras) y mixtas, cuando el aprendizaje se mide mediante el reconocimiento (Emmerich \& Ackerman, 1979; McDaniel \& Einstein, 1986, Worthen \&Wood, 2001). Sin embargo, Michelon, Snyder, Buckner, McAvoy y Zacks (2003) encontraron un efecto significativo de lo raro cuando se mide la memoria de reconocimiento después de dos días.

Quizás los resultados más interesantes de la memoria de reconocimiento con imágenes normales o raras es la que se refiere a los falsos reconocimientos (Worthen, 2006). Engelkamp, Zimmer y Biegelmann 
(1993), y Engelkamp, Zimmer, Mohr y Sellen (1994) encontraron más falsos reconocimientos para imágenes normales que para raras cuando las tareas eran descritas verbalmente (los sujetos aprendían las frases escuchándolas), sin embargo, no existió diferencia entre los dos tipos de imágenes cuando los sujetos desarrollaban la tarea (aunque sin objetos reales). Thomas y Loftus (2002) encontraron que no existían diferencias significativas en falso reconocimiento entre actos comunes y raros, tanto cuando se efectuaban como cuando se imaginaban.

Mercer (1996), después de una revisión histórica sobre la eficacia de las imágenes raras en la memoria, concluye que las imágenes raras son más efectivas en el recuerdo libre que en el reconocimiento, más efectivas en el recuerdo inmediato ( 5 minutos o menos) que a largo plazo, y más efectivas con listas mixtas que con listas puras. A estas tres condiciones, Burns (1996) añade una cuarta, que las imágenes raras son efectivas si el aprendizaje es incidental y no intencional.

A partir de la década de los 80 se han utilizado otras medidas de memoria, además del recuerdo y del reconocimiento, para ver la eficacia de las imágenes raras. Estas medidas son: acceso a la oración (una oración era puntuada como accedida si al menos una palabra de la oración era recordada), ítems recordados por oración, y oraciones completamente recordadas (si todas las palabras estímulo de la oración eran recordadas). McDaniel y Einstein (1986) encontraron que había un mayor acceso a la oración con imágenes raras que con imágenes normales en un diseño intralista, pero no había diferencias comparando listas. Las oraciones raras eran mejor accedidas que la oraciones comunes en listas mixtas, pero no en listas puras (McDaniel \& Einstein, 1991).

McDaniel y Einstein (1986) no encontraron el efecto de lo raro, sobre el número de items recordados por oración, tanto con diseños intralista, como con diseños entre listas. Tampoco se encontraron diferencias significativas en el número de ítems recordados por oración en función de la longitud de las listas (6 o 12 oraciones), y si las listas eran puras o mixtas (McDaniel \& Einstein, 1991). Sharpe y Markham (1992) no encontraron diferencias significativas en el número de ítems recordados por oración entre listas puras o mixtas.

Campos, Amor y González (2004), siguiendo a Ashcraft (1998) interpretan el rápido olvido de las estrategias mediante imágenes mentales en términos de la teoría de Tulving $(1972,1989,1993)$ sobre la memoria episódica, caracterizada por un fácil recuerdo inmediato y un pronto olvido. Los materiales codificados visualmente son muy susceptibles de interferencia con el tiempo, de ahí el rápido olvido.

Con la finalidad de evitar la interferencia y el olvido que provocan las imágenes mentales, Campos, Gómez-Juncal y Pérez-Fabello (2007, en prensa) comenzaron una serie de investigaciones que pretendían, mediante la repetición durante diferentes días, del material a aprender, consolidar lo aprendido con anterioridad, de tal modo que sea más difícil de olvidar. Campos et al. (en prensa) utilizaron sujetos altos en viveza de imagen y aprendizaje incidental, mediante imágenes normales, raras y mixtas. Encontraron el efecto de lo raro después de una semana, tanto en recuerdo como en el número de oraciones totalmente recordadas, y en el acceso a la oración. Sin embargo, no encontraron el efecto de lo raro, después de un día y de una semana, en el número de items recordados por oración, ni en el reconocimiento. Campos et al. (2007) también utilizaron grupos de sujetos para aprender oraciones, mediante el método de repetición, imágenes normales, raras, y mixtas, utilizando aprendizaje intencional y listas largas. Encontraron que el grupo que utilizó imágenes raras tuvo, al cabo de una semana, un recuerdo, reconocimiento, acceso a la oración, número de ítems recordados por oración, y a un número de oraciones totalmente recordadas superior a los grupos que utilizaron imágenes normales o no utilizaron imágenes mentales. El grupo que no utilizó imágenes mentales tuvo una mayor proporción de falsas alarmas que los otros grupos.

En esta investigación, siguiendo la línea de las investigaciones precedentes (Campos et al., 2007, en prensa), deseábamos averiguar si, inmediatamente después del aprendizaje incidental, después de un día y de una semana, existía diferencia en memoria entre los individuos con y sin experiencia en la utilización de imágenes. También deseábamos averiguar si existía diferencia entre diferentes estrategias de imagen: sin imagen, imagen normal, imagen rara e imagen mixta, cuando además del aprendizaje existía reaprendizaje incidental. 


\section{Método}

\section{Participantes}

La muestra estaba formada por 198 sujetos (104 mujeres y 94 hombres), alumnos de Educación Secundaria Obligatoria, con una media de 14.4 años (desviación típica $(D P)=1.12$ ), y un rango de 12 a 17 años. En el tratamiento de los sujetos y de los datos se han seguido los principios éticos del psicólogo y el código de conducta del trabajo científico.

\section{Materiales}

Utilizamos una lista de 96 palabras seleccionadas al azar del Diccionario de la Lengua Española, con la única condición de que fuesen sustantivos. Con la mitad de estas palabras (48), también seleccionadas al azar, nosotros construimos 3 listas con 16 oraciones simples cada una. Cada oración contenía 3 palabras de la lista de 48 palabras. Las palabras eran las mismas en las tres listas y estaban escritas en letras mayúsculas. Una lista describía una situación normal, otra describía una situación atípica, y una tercera era una mezcla de las dos anteriores. Para crear estas frases se respetaron los tiempos de los verbos, los artículos determinados y indeterminados, el singular o plural, etc., entre las tres listas. La media de palabras por oración de la lista normal fue de 7.56 (DP=0.89), y la media de palabras por oración de la lista rara (atípica) fue de $7.56(\mathrm{DP}=0.96)$. No existió diferencia significativa entre las listas normales y raras en el número de palabras, $t(15)=0.001, p>0.05$. La correlación entre las oraciones normales y raras en el número de palabras fue de $0.77, p<0.001$. Las otras 48 palabras que no se utilizaron en el aprendizaje, se utilizaron posteriormente para la prueba de reconocimiento.

\section{Procedimientos}

La muestra de sujetos fue distribuida al azar en cuatro grupos: el grupo sin imagen debía leer cada oración, fijarse en las tres palabras escritas en mayúsculas y puntuar la relación que existía entre las tres palabras, en una escala de 5 puntos. El segundo grupo tenía que formar imágenes normales, el tercer grupo tenía que formar imágenes raras, y el cuarto formar imágenes normales y raras (grupo mixto), y puntuar la viveza de la imagen suscitada por cada oración en una escala de 5 puntos, donde el 1 no indicaba ninguna imagen, y el 5 indicaba imagen perfectamente clara y viva. La puntuación en viveza no se analizó, sirvió únicamente como estrategia para el aprendizaje incidental. Para esta tarea contaron con 15 segundos por oración, aspecto que se ensayó con 5 oraciones de entrenamiento en el momento en el que los sujetos recibían las instrucciones. El tiempo total de duración de esta tarea fue de 4 minutos. A los sujetos no se les comunicó en ningún momento que debían aprender la lista de palabras, ya que se trataba de un aprendizaje incidental.

La instrucción dada a los sujetos que tenían que formar imágenes raras fue la siguiente: "El propósito de esta investigación es averiguar la diferencia en imagen entre los individuos. Lo que tenéis que hacer es leer el contenido de cada oración, a continuación formar una imagen mental de ese contenido, y posteriormente puntuar la claridad o viveza de la imagen en la escala de 5 puntos que tienes a continuación" (a continuación se presentó la escala). Un ejemplo de frase rara y de la forma de presentarla es el siguiente: "El CABALLO bebió LECHE de la BOTELLA". Las demás instrucciones de imagen eran semejantes, lo que varió fue la frase.

Tras la presentación de las oraciones se presentó a los sujetos una tarea distractora que consistió en un par de dibujos en los que había que encontrar diferencias, durante un tiempo de 2 minutos. Transcurrido este período, los sujetos debían recordar, lo más exactamente posible, el máximo de oraciones que habían leído y puntuado anteriormente. También se les preguntó si utilizaban habitualmente alguna estrategia de imagen para aprender algo, por ejemplo, para aprender una lista de palabras. La respuesta a esta pregunta nos indicó la experiencia que los sujetos tenían en el uso de imágenes mentales en tareas de aprendizaje. Si los sujetos contestaban que tenían experiencia en la utilización de imágenes eran incluidos en el grupo de sujetos "con experiencia" en la utilización de imágenes mentales, y si contestaban que no las utilizaban habitualmente, se incluyeron en el grupo "sin experiencia". Para toda esta tarea los sujetos contaron con 5 minutos.

Después de la prueba de recuerdo, los sujetos debían realizar un test de reconocimiento. En esta prueba 
los sujetos debían reconocer entre 96 palabras, las 48 palabras que se le habían presentado en letras mayúsculas en las oraciones. Para completar esta prueba, los sujetos contaron con un tiempo de 5 minutos. En una segunda sesión, al cabo de un día, y sin que los sujetos fuesen informados de ello, realizaron, de nuevo, las pruebas de recuerdo y de reconocimiento. Contaron con 5 minutos para cada una de ellas. Al final de esta sesión, los sujetos realizaron una segunda tarea de reaprendizaje incidental, que consistió, nuevamente, en valorizar la relación entre las palabras de la oración, o la viveza de imagen de cada oración. Seis días después de esta segunda sesión, se presentó a los sujetos, sin previo aviso, el test de recuerdo y el test de reconocimiento. Para cada una de estas pruebas los sujetos dispusieron de 5 minutos. Las pruebas se realizaron en el aula habitual en la que tenían clases, y todos los sujetos fueron voluntarios.

Finalizadas las pruebas, se corrigieron los resultados mediante 5 medidas: a) Recuerdo. Número de palabras recordadas correctamente. Se admitieron como correctas las variantes plural/singular, masculino/ femenino de cada palabra, pero no se consideraron como correctos los sinónimos; b) Reconocimiento. Para el análisis utilizamos la proporción de palabras correctamente reconocidas, mediante la siguiente fórmula: [Puntuación de reconocimiento $=p$ (Aciertos) $-p$ (Falsas alarmas)/1 - p(Falsas alarmas)] (Einstein, McDaniel \& Lackey, 1989; Zechmeister \& Nyberg, 1982); c) Falso reconocimiento. Se asignó un punto a cada palabra que el sujeto identificaba como correcta siendo falsa (utilizamos la proporción de falsos reconocimientos); d) Acceso a la oración. Se asignó un punto a cada oración si el sujeto recordaba, al menos, una de las tres palabras en mayúsculas que formaban parte de la oración; e) Ítems recordados por oración. La puntuación consistió en dividir el número total de palabras recordadas (recuerdo) entre el número de oraciones que contenía, al menos, una palabra en mayúscula recordada (acceso a la oración); f) Número de oraciones totalmente recordadas. Se asignó un punto a cada oración si incluía las tres palabras en mayúsculas recordadas correctamente.

\section{Resultados}

Recuerdo. Para analizar si existía diferencia en recordar entre las puntuaciones obtenidas por los sujetos con y sin experiencia en la utilización de imágenes, y entre los diferentes grupos de imagen, efectuamos un MANOVA de 2 (con y sin experiencia) $\times 4$ (estrategia de imagen: sin imagen, imagen normal, imagen rara, y mixta). Como variables dependientes utilizamos el recuerdo inmediato, después de un día y después de una semana. La Raíz mayor de Roy indicó la existencia de diferencias significativas en el recuerdo en función de la experiencia en la utilización de imágenes, Raíz mayor de Roy=0.06, $F(3,188)=3.665$, $p<0.05$, potencia $=0.80$. Las medias y desviaciones típicas se encuentran en la Tabla 1. Los análisis univariados indican que la experiencia influyó en el recuerdo al cabo de un día y de una semana. Los sujetos con experiencia en la utilización de imágenes tuvieron, al cabo de un día, mayor recuerdo, $F(1,198)=6.617, p<0.01$, potencia $=0.73$, que los sujetos sin experiencia. Y, al cabo de una semana, los sujetos con experiencia en la utilización de imágenes tuvieron mayor recuerdo, $F(1,198)=7.189, p<0.01$, potencia $=0.76$, que los sujetos sin experiencia.

La Raíz mayor de Roy también indicó que existían diferencias significativas en recuerdo en función de la estrategia de imagen utilizada: sin imagen, imagen normal, imagen rara, e imagen mixta, Raíz mayor de Roy $=0.09, F(3,190)=5.775, p<0.001$, potencia $=0.95$. Las medias y desviaciones típicas de recuerdo en función de la estrategia de imagen se encuentran en la Tabla 2. Los análisis univariados indican que la estrategia de imagen influye en el recuerdo inmediato, $F(3,190)=3.291$, $p<0.05$, potencia $=0.80$, en el recuerdo al cabo de un día, $F(3,190)=4.719, p<0.01$, potencia $=0.89$, y en el recuerdo al cabo de una semana, $F(3,190)=5.727, p<0.001$, potencia $=0.95$. El análisis de la Diferencia Menos Significativa (DMS) indicó $(p<0.05)$ que, en recuerdo inmediato, sólo existió diferencia significativa del grupo mixto con el grupo sin imagen y con el grupo de imagen normal. Los sujetos del grupo mixto tuvieron un mayor recuerdo de palabras que el grupo con imagen normal y del grupo sin imagen. Al cabo de un día, el resultado fue que se encontró que el grupo que utilizó imágenes raras tuvo mayor recuerdo que el grupo que utilizó imágenes normales, y el grupo de imagen mixta tuvo mayor recuerdo que el grupo sin imagen y que del grupo de imagen normal. Al cabo de una semana, el grupo de imagen rara recordó 
significativamente más palabras que el grupo sin imagen y que el grupo con imagen normal, y el grupo mixto recordó significativamente más palabras que el grupo sin imagen y el grupo de imagen normal. No hemos encontrado interacción entre la experiencia en la utilización de imágenes y el tipo de estrategia utilizada.

Reconocimiento. Efectuamos un MANOVA de 2 (con y sin experiencia) $\times 4$ (estrategia de imagen: $\sin$ imagen, imagen normal, imagen rara, y mixta). Como variables dependientes utilizamos el reconocimiento correcto inmediatamente, después de un día, y después de una semana. La Raíz mayor de Roy indicó la existencia de diferencias significativas en el reconocimiento en función de la experiencia en la utilización de imágenes, Raíz mayor de Roy=0.04 F(3, 188)=2.783, $p<0.05$, potencia $=0.67$. Las medias de reconocimiento de los grupos con y sin experiencia se encuentran en la Tabla 1. Los análisis univariados indican que la experiencia influyó en el reconocimiento al cabo de un día y de una semana. Los sujetos con experiencia en la utilización de imágenes tuvieron, al cabo de un día, mayor reconocimiento, $F(1,190)=4.506, p<0.05$, potencia $=0.56$, que los sujetos sin experiencia. Después de una semana, los sujetos con experiencia en la utilización de imágenes tuvieron mayor reconocimiento, $F(1,190)=7.991, p<0.01$, potencia $=0.80$, que los sujetos sin experiencia en la utilización de imágenes.

La Raíz mayor de Roy indicó que existían diferencias significativas en reconocimiento en función de la estrategia de imagen utilizada: sin imagen, imagen normal, imagen rara, e imagen mixta, Raíz mayor de Roy $=0.08, F(3,190)=5.299, p<0.01$, power $=0.93$. Las medias y desviaciones típicas de reconocimiento en función de la estrategia de imagen se encuentran en la Tabla 2. Los análisis univariados indican que la estrategia de imagen influye en el reconocimiento al cabo de un día, $F(3,190)=4.650, p<0.01$, potencia=0.89, y en el reconocimiento al cabo de una semana, $F(3,190)=3.604$, $p<0.05$, potencia $=0.79$. Diferencia Menos Significativa (DMS) indicó $(p<0.05)$ que, en reconocimiento al cabo de un día, se encontró que el grupo que utilizó imágenes raras tuvo mayor reconocimiento que el grupo que utilizó imágenes normales, y el grupo de imagen mixta tuvo mayor reconocimiento que el grupo sin imagen y que del grupo de imagen normal. Y, al cabo de una semana, el grupo de imagen rara reconoció significativamente más palabras que el grupo sin imagen y que el grupo con imagen normal, y el grupo mixto reconoció significativamente más palabras que el grupo sin imagen y que el grupo de imagen normal. Encontramos significativa interacción entre la experiencia en la utilización de imágenes y el tipo de estrategia utilizada, Raíz mayor de Roy=0.06, F(3, 190) $=3.549, p<0.05$, potencia $=0.78$, sin embargo, los análisis univariados no encontraron la interacción significativa en ninguno de los tres momentos.

Falso reconocimiento. Para analizar si existían diferencias significativas en la proporción de falsos reconocimientos, efectuamos un MANOVA de 2 (con y sin experiencia) x 4 (estrategia de imagen: sin imagen, imagen normal, imagen rara, e imagen mixta). Las medias y desviaciones típicas de los sujetos con y sin experiencia se encuentran en la Tabla 1, y de los sujetos según su estrategia de aprendizaje se encuentran en la Tabla 2. La Raíz mayor de Roy indicó que no existían diferencias significativas $(p>0.05)$ en el falso reconocimiento en función de la experiencia en la utilización de imágenes. Sin embargo, encontramos diferencias significativas entre los grupos en función de la estrategia de imagen utilizada: sin imagen, imagen normal, imagen rara, e imagen mixta, Raíz mayor de Roy $=0.07, F(3,190)=4.554, p<0.01$, potencia $=0.88$. Los análisis univariados indican que la estrategia de imagen influye tanto en el falso reconocimiento inmediato, $F(3$, $190)=2.920, p<0.05$, potencia $=0.69$, como en el falso reconocimiento al cabo de un día, $F(3,190)=4.471, p<0.01$, potencia $=0.88$, y en el falso reconocimiento al cabo de una semana, $F(3,190)=2.954, p<0.05$, potencia $=0.69$. El análisis de la Diferencia Menos Significativa (DMS) indicó $(p<0.05)$ que los sujetos que no utilizaron imágenes tuvieron, inmediatamente después del aprendizaje, mayor proporción de falsos reconocimientos que los sujetos que utilizaron imágenes raras y que los que utilizaron imágenes mixtas, y los sujetos que utilizaron imágenes normales tuvieron mayor proporción de falsos reconocimientos que los sujetos que utilizaron imágenes mixtas. Al cabo de un día, el grupo que utilizó imágenes normales tuvo una mayor proporción de falsos reconocimientos que el grupo que utilizó imágenes raras e imágenes mixtas, y el grupo sin imagen tuvo más falsos reconocimientos que el grupo que utilizó 
imágenes mixtas. Y, al cabo de una semana, los grupos que no utilizaron imágenes y los que utilizaron imágenes normales, tuvieron mayor falso reconocimiento que los grupos que utilizaron imágenes raras o los que utilizaron imágenes mixtas. La interacción entre la experiencia en la utilización de imágenes y la estrategia de imagen utilizada en el aprendizaje no resultaron significativas.

Tabla 1. Medias (M) y desviaciones típicas (DP) (entre paréntesis) de diferentes medidas de memoria inmediatamente, al cabo de un día y de una semana, de sujetos con y sin experiencia.

\begin{tabular}{|c|c|c|c|c|c|c|c|c|c|c|c|c|}
\hline \multirow{3}{*}{$\begin{array}{l}\text { Medidas de } \\
\text { memoria }\end{array}$} & \multicolumn{4}{|c|}{ Inmediatamente } & \multicolumn{4}{|c|}{ Un Dia } & \multicolumn{4}{|c|}{ Una Semana } \\
\hline & \multicolumn{2}{|c|}{ Con exper $(n=102)$} & \multicolumn{2}{|c|}{ Sin Exper $(n=96)$} & \multicolumn{2}{|c|}{ Con exper $(n=102)$} & \multicolumn{2}{|c|}{ Sin Exper $(n=96)$} & \multicolumn{2}{|c|}{ Con exper $(n=102)$} & \multicolumn{2}{|c|}{ Sin Exper $(n=96)$} \\
\hline & M & $\mathrm{DP}$ & $M$ & $\mathrm{DP}$ & M & $\mathrm{DP}$ & $M$ & $\mathrm{DP}$ & $\mathrm{M}$ & $\mathrm{DP}$ & $M$ & $\mathrm{DP}$ \\
\hline Recuerdo & 17.99 & 7.73 & 16.31 & 7.75 & 23.73 & 10.09 & 19.67 & 10.04 & 28.61 & 12.43 & 23.65 & 11.91 \\
\hline Reconocimiento & 0.74 & 0.15 & 0.69 & 0.19 & 0.72 & 0.21 & 0.62 & 0.30 & 0.78 & 0.23 & 0.64 & 0.36 \\
\hline Falso reconocim & 0.04 & 0.05 & 0.04 & 0.05 & 0.07 & 0.08 & 0.10 & 0.11 & 0.08 & 0.09 & 0.11 & 0.14 \\
\hline Acceso oración & 6.80 & 2.67 & 6.08 & 2.71 & 8.88 & 3.41 & 7.46 & 3.51 & 10.52 & 4.18 & 8.72 & 3.99 \\
\hline Items por oración & 2.64 & 0.31 & 2.65 & 0.31 & 2.64 & 0.28 & 2.59 & 0.33 & 2.71 & 0.27 & 2.60 & 0.51 \\
\hline Orac tot record & 4.77 & 2.64 & 4.35 & 2.51 & 6.23 & 3.52 & 5.10 & 3.30 & 8.08 & 4.26 & 6.53 & 3.85 \\
\hline
\end{tabular}

Con exper: con experiencia; Sin exper: sin experiencia.

Tabla 2. Medias (M) y desviaciones típicas (DP) (entre paréntesis) de diferentes medidas de memoria inmediatamente, al cabo de un día y de una semana, según la estrategia de aprendizaje.

\begin{tabular}{|c|c|c|c|c|c|c|c|c|}
\hline \multirow{3}{*}{$\begin{array}{l}\text { Medidas de } \\
\text { memoria }\end{array}$} & \multicolumn{8}{|c|}{ Inmediatamente } \\
\hline & \multicolumn{2}{|c|}{$1(n=53)$} & \multicolumn{2}{|c|}{$2(n=63)$} & \multicolumn{2}{|c|}{$3(n=49)$} & \multicolumn{2}{|c|}{$4(n=41)$} \\
\hline & M & DP & $M$ & DP & $M$ & DP & $M$ & $\mathrm{DP}$ \\
\hline Recuerdo & 16.64 & 10.09 & 15.46 & 7.05 & 17.37 & 6.68 & 19.88 & 5.43 \\
\hline Reconocimiento & 0.71 & 0.19 & 0.68 & 0.19 & 0.73 & 0.15 & 0.77 & 0.12 \\
\hline Falso reconocim & 0.06 & 0.05 & 0.05 & 0.05 & 0.04 & 0.05 & 0.03 & 0.03 \\
\hline Acceso oración & 6.23 & 3.43 & 5.92 & 2.52 & 6.43 & 2.40 & 7.41 & 1.91 \\
\hline Items por oración & 2.60 & 0.41 & 2.62 & 0.30 & 2.70 & 0.25 & 2.68 & 0.22 \\
\hline Orac tot record & 4.43 & 3.38 & 4.02 & 2.36 & 4.61 & 2.20 & 5.39 & 1.86 \\
\hline \multirow{3}{*}{$\begin{array}{l}\text { Medidas de } \\
\text { memoria }\end{array}$} & \multicolumn{8}{|c|}{ Un Dia } \\
\hline & \multicolumn{2}{|c|}{$1(n=53)$} & \multicolumn{2}{|c|}{$2(n=63)$} & \multicolumn{2}{|c|}{$3(n=49)$} & \multicolumn{2}{|c|}{$4(n=41)$} \\
\hline & $M$ & DP & $\mathrm{M}$ & $\mathrm{DP}$ & $\mathrm{M}$ & DP & $M$ & $\mathrm{DP}$ \\
\hline Recuerdo & 20.23 & 12.96 & 19.24 & 8.92 & 22.92 & 8.67 & 26.07 & 7.74 \\
\hline Reconocimiento & 0.65 & 0.24 & 0.58 & 0.34 & 0.73 & 0.17 & 0.77 & 0.16 \\
\hline Falso reconocim & 0.09 & 0.09 & 0.12 & 0.12 & 0.06 & 0.07 & 0.05 & 0.05 \\
\hline Acceso oración & 7.47 & 4.16 & 7.24 & 3.02 & 8.78 & 3.20 & 9.83 & 2.84 \\
\hline Items por oración & 2.59 & 0.43 & 2.61 & 0.30 & 2.61 & 0.20 & 2.65 & 0.19 \\
\hline Orac tot record & 5.51 & 4.66 & 5.00 & 3.06 & 5.69 & 2.76 & 6.83 & 2.44 \\
\hline \multirow{3}{*}{$\begin{array}{l}\text { Medidas de } \\
\text { memoria }\end{array}$} & \multicolumn{8}{|c|}{ Una Semana } \\
\hline & \multicolumn{2}{|c|}{$1(n=53)$} & \multicolumn{2}{|c|}{$2(n=63)$} & \multicolumn{2}{|c|}{$3(n=49)$} & \multicolumn{2}{|c|}{$4(n=41)$} \\
\hline & $M$ & DP & $M$ & DP & $M$ & DP & $M$ & $\mathrm{DP}$ \\
\hline Recuerdo & 23.38 & 14.68 & 23.11 & 11.27 & 28.35 & 10.90 & 31.76 & 9.30 \\
\hline Reconocimiento & 0.67 & 0.28 & 0.63 & 0.32 & 0.80 & 0.17 & 0.79 & 0.35 \\
\hline Falso reconocim & 0.12 & 0.11 & 0.12 & 0.13 & 0.07 & 0.08 & 0.07 & 0.13 \\
\hline Acceso oración & 8.58 & 4.88 & 8.55 & 3.68 & 10.45 & 3.79 & 11.61 & 3.18 \\
\hline Items por oración & 2.63 & 0.54 & 2.65 & 0.32 & 2.65 & 0.44 & 2.72 & 0.22 \\
\hline Orac tot record & 6.74 & 4.99 & 6.37 & 3.77 & 7.82 & 3.58 & 8.88 & 3.24 \\
\hline
\end{tabular}

1: Sin imagen; 2: Imagen normal ; 3: Imagen rara; 4: Imagen mixta. 
Acceso a la oración. Para analizar si existían diferencias entre los grupos en el acceso a la oración, efectuamos un MANOVA de 2 (con y sin experiencia) x 4 (estrategia de imagen: sin imagen, imagen normal, imagen rara, e imagen mixta). Como variables dependientes utilizamos el acceso a la oración inmediatamente, al cabo de un día y de una semana. Las medias de los grupos con y sin experiencia, y en función de la estrategia de aprendizaje se encuentran en las Tablas 1 y 2. La Raíz mayor de Roy indicó que existían diferencias significativas en función de la experiencia, Raíz mayor de Roy=0.05, F(3, 187)=3.191, $p<0.05$, potencia $=0.73$. Los análisis univariados indicaron que la experiencia influyó significativamente $(p<0.05)$ en el acceso a la oración al cabo de un día y de una semana. Los sujetos con experiencia mostraron, al cabo de un día, mayor acceso a la oración, $F(1,189)=6.702$, $p<0.01$, potencia $=0.73$, que los sujetos sin experiencia. Al cabo de una semana, los sujetos con experiencia manifestaron un mayor acceso a la oración, $F(1$, $189)=8.444, p<0.01$, potencia $=0.82$, que los sujetos $\sin$ experiencia.

Los resultados del MANOVA también indicaron que la estrategia utilizada: sin imagen, imagen normal, imagen rara, e imagen mixta, también influía en el acceso a la oración, Raíz mayor de Roy=0.11, $F(3,189)=7.020$, $p<0.001$, potencia $=0.98$. Los análisis univariados indicaron que existía diferencia significativa entre los grupos en función de la estrategia de imagen en los tres momentos: inmediatamente, $F(3,189)=3.114, p<0.05$, potencia $=0.72$, al cabo de un día, $F(3,189)=6.021, p<0.001$, potencia $=0.96$, $y$ al cabo de una semana, $F(3,189)=6.530$, $p<0.001$, potencia $=0.97$. El análisis de la Diferencia Menos Significativa (DMS) indicó $(p<0.05)$ que, en el acceso a la oración inmediato, existió diferencia del grupo mixto con el grupo sin imagen y con el grupo de imagen normal. Los sujetos del grupo mixto tuvieron un mayor acceso a la oración que el grupo con imagen normal y del grupo sin imagen. Después de un día, se encontró que el grupo que utilizó imágenes raras tuvo mayor acceso a la oración que el grupo que utilizó imágenes normales y el grupo sin imagen, y el grupo mixto tuvo un mayor acceso a la oración que el grupo que utilizó imágenes normales y el grupo sin imagen. Al cabo de una semana, el grupo de imagen rara tuvo un mayor

328 acceso a la oración que el grupo sin imagen y que el grupo con imagen normal, y el grupo mixto tuvo mayor acceso a la oración que el grupo sin imagen y el grupo de imagen normal. La interacción entre la experiencia y la estrategia resultó significativa, Raíz mayor de Roy=0.47, $F(3,189)=2.882, p<0.05$, potencia $=0.68$, sin embargo, los análisis univariados no resultaron significativos.

Items recordados por oración. Para ver si existía diferencia en el número de ítems recordados por oración entre los sujetos con experiencia y sin ella, y entre los distintos grupos de imagen, efectuamos un MANOVA de 2 (con y sin experiencia) x 4 (estrategia de imagen: sin imagen, imagen normal, imagen rara, e imagen mixta). Como variables dependientes utilizamos el número de ítems recordados por oración inmediatamente, después de un día, y después de una semana. Las medias y desviaciones típicas de los sujetos con y sin experiencia, y de los sujetos en función de su estrategia de aprendizaje se encuentran en las Tablas 1 y 2. No hemos encontrado diferencias significativas ( $p>0.05$ ) entre ningún grupo, ni en la interacción entre la experiencia y los grupos de imagen.

Oraciones totalmenterecordadas. La continuación, analizamos si existían diferencias significativas en el número de oraciones totalmente recordadas, obtenidas por los sujetos con y sin experiencia en la utilización de imágenes, y entre los distintos grupos de imagen. Para ello, efectuamos un MANOVA de 2 (con y sin experiencia) x 4 (estrategia de imagen: sin imagen, imagen normal, imagen rara, e imagen mixta). Como variables dependientes utilizamos el número de oraciones totalmente recordadas inmediatamente, después de un día, y después de una semana. Las medias de las oraciones totalmente recordadas obtenidas por los sujetos con y sin experiencia, y en función de la estrategia de imagen utilizada, se encuentran en las Tablas 1 y 2. La Raíz mayor de Roy indicó que existían diferencias significativas en función de la experiencia, Raíz mayor de Roy=0.05, $F(3,188)=3.119, p<0.05$, potencia $=0.72$. Los análisis univariados indicaron que la experiencia influyó en el número de oraciones totalmente recordadas después de un día y de una semana. Los sujetos con experiencia mostraron, al cabo de un día, mayor número de oraciones totalmente recordadas, $F(1,190)=4.183, p<0.05$, potencia $=0.53$, que los sujetos sin experiencia. Al cabo de una semana, los sujetos con experiencia manifestaron un mayor número 
de oraciones totalmente recordadas, $F(1,190)=5.964$, $p<0.05$, potencia $=0.68$, que los sujetos sin experiencia.

El MANOVA también indicó que la estrategia utilizada: sin imagen, imagen normal, imagen rara, e imagen mixta, también influía en el número de oraciones totalmente recordadas, Raíz mayor de Roy $=0.06, F(3,190)=3.946, p<0.01$, potencia $=0.83$. Los análisis univariados indicaron que sólo existía diferencia significativa entre los grupos en función de la estrategia de imagen, en el número de oraciones totalmente recordadas después de una semana, $F(3,190)=3.746$, $p<0.05$, potencia $=0.80$. El análisis de la Diferencia Menos Significativa (DMS) indicó ( $p<0.05)$ que con las imágenes raras se obtuvo, después de una semana, un mayor número de oraciones totalmente recordadas que con imágenes normales, y con imágenes mixtas se obtuvo mayor número de oraciones totalmente recordadas que con imagen normal y sin imagen.

\section{Discusión}

Los sujetos con experiencia en la utilización de imágenes tuvieron mejores resultados que los sujetos sin experiencia. Este resultado se observa al cabo de un día y de una semana en el recuerdo, en el reconocimiento, y en las oraciones totalmente recordadas, lo que corrobora los estudios sobre la importancia del entrenamiento en imágenes mentales para conseguir un mejor recuerdo (Katz, 1983; Paivio, 1986; A. A. Sheikh \& K. S. Sheikh, 1985; Sheikh et al., 2002).

Cuando utilizamos como variable dependiente el recuerdo, no hemos encontrado diferencia significativa entre las imágenes raras y las demás estrategias en el recuerdo inmediato. Este resultado coincide con los estudios existentes (Campos et al., 2007, en prensa; Cox\&Wollen, 1981; McDaniel \& Einstein, 1986; Wollen \& Cox, 1981). Al cabo de una semana, el grupo que utilizó imágenes raras y el que utilizó imágenes mixtas manifestaron mayor recuerdo que los grupos que utilizaron imágenes normales o no utilizaron imágenes mentales. Estos resultados están en la línea con los estudios que encontraron el efecto de lo raro a largo plazo (Campos et al., 2007, en prensa; laccino et al., 1989; Marshall et al.,1980; Merry, 1980; Merry \& Graham, 1978; O’Brien \&Wolford, 1982; Sharpe \& Markham, 1992).
Cuando se ha estudiado el efecto de lo raro en el reconocimiento, en general no se ha encontrado una superioridad de las imágenes raras sobre las normales (Emmerich \& Ackerman, 1979; McDaniel \& Einstein, 1986; Worthen \& Wood, 2001). Sin embargo, nosotros hemos encontrado, al cabo de un día, que las imágenes raras y mixtas eran superiores a las imágenes normales. Al cabo de una semana, las imágenes raras y mixtas fueron superiores a las imágenes normales y al grupo sin imagen. Por lo tanto, encontramos el efecto de lo raro en el reconocimiento después de una semana. Nuestro resultado coincide con el de Michelon et al. (2003) que encontró el efecto de lo raro mediante el reconocimiento después de dos días, y coincide también con los resultados de Campos et al. (2007) que encontró el mismo resultado al cabo de una semana utilizando el aprendizaje intencional.

Al analizar los falsos reconocimientos hemos encontrado que tanto inmediatamente, como al cabo de un día y de una semana, las imágenes raras y las imágenes mixtas fueron las que obtuvieron un menor número de falsos reconocimientos. Estos resultados corroboran los estudios de Engelkamp et al. (1993) y Engelkamp et al. (1994) que encontraron que las imágenes normales producían más falsos reconocimientos, tanto inmediatamente, como al cabo de 30 minutos, que las imágenes raras. Los resultados también coinciden con el estudio de Campos et al. (2007) que encontró, al cabo de una semana, que el grupo que no utilizó imágenes mentales tuvo mayor número de falsos reconocimientos que el grupo que utilizó imágenes raras e imágenes normales.

Los grupos que utilizaron imágenes raras o imágenes mixtas tuvieron, después de un día y después de una semana, una mayor proporción de acceso a la oración que los grupos que no utilizaron imágenes o utilizaron imágenes normales. Estos resultados están en la línea general de las investigaciones precedentes que encontraron que las imágenes raras manifestaron una mayor proporción de oraciones accedidas que las imágenes normales, o que los grupos que no utilizan imágenes mentales (Campos et al., 2007, en prensa; McDaniel \& Einstein, 1986, 1991).

No hemos encontrado diferencias significativas en el número de ítems recordados por oración en ninguno de los grupos. Este resultado se une al que se 
ha obtenido en la casi totalidad de las investigaciones que se han efectuado hasta el momento (Campos et al., en prensa; Imai \& Richman, 1991; McDaniel \& Einstein,1986, 1991; Sharpe \& Markham; 1992). El único trabajo que encontró el efecto de lo raro en el número de ítems recordados por oración fue el de Campos et al. (2007). En este estudio, los autores no encontraron el efecto de lo raro en el número de ítems recordados por oración inmediatamente, ni al cabo de un día, sin embargo, lo encontraron al cabo de una semana utilizando imágenes raras y con reaprendizaje del material. Con imágenes mixtas tampoco encontraron el efecto de lo raro.

Al analizar la diferencia entre los grupos en el número de oraciones totalmente recordadas, sólo hemos encontrado el efecto de lo raro después de una semana. Las imágenes raras fueron superiores a las normales en el número de oraciones totalmente recordadas, y las listas mixtas fueron superiores a las normales y al grupo sin imagen. Resultados similares fueron encontrados en otras investigaciones por Campos et al. (2007, en prensa), que sólo encontraron el efecto de lo raro después de una semana.

Pensamos que esta nueva línea de investigación ofrece resultados muy prometedores, de hecho, si observamos el efecto de lo raro en todas las variables dependientes, encontramos que tanto las imágenes raras y mixtas (las dos que utilizan imágenes raras) tuvieron, después de una semana (después de varias repeticiones), diferencias significativas con las imágenes normales o con el grupo que no utilizó imágenes mentales. Esto se observa en todas las medidas utilizadas, excepto en el número de ítems recordados por oración. También resultan prometedores los resultados encontrados con la experiencia. Pensamos que se necesitan nuevas investigaciones que analicen la importancia para el aprendizaje, de la familiaridad con las imágenes mentales, ya sea mediante la experiencia o el entrenamiento. También se necesitan nuevos estudios que analicen el efecto de lo raro a través de la repetición del aprendizaje, y no el efecto de lo raro en el aprendizaje con un solo ensayo.

\section{Referencias}

Andreoff, G. R., \& Yarmey, A. D. (1976). Bizarre imagery and associative learning: a confirmation. Perceptual and Motor Skills, 43 (1), 143-148.
Ashcraft, M. H. (1998). Fundamentals of cognition. New York: Longman.

Burns, D. J. (1996). The bizarre imagery effect and intention to learn. Psychonomic Bulletin \& Review, 3 (2), 254-257.

Campos, A., Amor, A., \& González, M. A. (2004). The importance of the keyword-generation method in keyword mnemonics. Experimental Psychology, 51 (2), 125-131.

Campos, A., Gómez-Juncal, R., \& Pérez-Fabello, M. J. (2007). The efficacy of imagery strategies on long-term recall and recognition. Manuscrito enviado a publicar.

Campos, A., Gómez-Juncal, R., \& Pérez-Fabello, M. J. (en prensa). Mnemotecnia mediante imágenes y aprendizaje incidental de sujetos altos en viveza de imagen. Adaxe.

Campos, A., González, M. A., \& Amor, A. (2004). Different strategies for keyword generation. Journal of Mental Imagery, 28 (3\&4), 51-58.

Collyer, S. C., Jonides, J., \& Bevan, W. (1972). Images as memory aids. Is bizarreness helpful? American Journal of Psychology, 85 (1), 31-38.

Cox, S. D., \& Wollen, K. A. (1981). Bizarreness and recall. Bulletin of the Psychonomic Society, 18 (5), 244-245.

Denis, M. (1991). Image and cognition. London: Harvester Wheatsheaf.

Einstein, G. O., McDaniel, M. A., \& Lackey, S. (1989). Bizarre imagery, interference, and distinctiveness. Journal of Experimental Psychology:Learning, Memory, and Cognition, 15 (1), 137-146.

Emmerich, H. J., \& Ackerman, B. P. (1979). A test of bizarre interaction as a factor in children's memory. Journal of Genetic Psychology, 134 (3), 225-232.

Engelkamp, J., Zimmer, H. D., \& Biegelmann, U. E. (1993). Bizarreness effects in verbal tasks and subject-performed tasks. European Journal of Cognitive Psychology, 5 (4), 393-415.

Engelkamp, J., Zimmer, H. D., Mohr, G., \& Sellen, O. (1994). Memory of self-performed task: Self-performing during recognition. Memory \& Cognition, 22 (1), 34-39.

Hampson, P. J., Marks, D. F., \& Richardson, J. T. E. (1990). Imagery. Current developments. New York: Routledge.

Higbee, K. L. (1993). Your memory. New York: Paragon House.

laccino, J. F., Dvorak, E., \& Coler, M. (1989). Effects of bizarre imagery on the long-term retention of paired associates embedded within variable contexts. Bulletin of the Psychonomic Society, 27 (2), 114-116.

Imai, S., \& Richman, C. L. (1991). Is the bizarreness effect a special case of sentence reorganization? Bulletin of the Psychonomic Society, 29 (5), 429-432.

Katz, A. (1983). What does it mean to be a high imager. In I. C. Yuille (Ed.), Imagery, memory and cognition: essays in honor of Allan Paivio (pp.39-63). Hillsdale, NJ: Erlbaum.

Kroll, N. E. A., Schepeler, E. M., \& Angin, K. T. (1986). Bizarre imagery: The misremembered mnemonic. Journal of Experimental Psychology:Learning, Memory and Cognition, $12(1), 42-53$ 
Marchal, A., \& Nicolas, S. (2000). Is the picture-bizarreness effect a generation effect? Psychological Reports, 87 (2), 331-340.

Marshall, P. H., Nau, K., \& Chandler, C. K. (1980). A functional analysis of common and bizarre visual mediators. Bulletin of the Psychonomic Society, 15 (6), 375-377.

McDaniel, M. A., \& Einstein, G. O. (1986). Bizarre imagery as an effective memory aid: the importance of distinctiveness. Journal of Experimental Psychology: Learning, Memory and Cognition, 12 (1), 54-65.

McDaniel, M. A., \& Einstein, G. O. (1991). Bizarre imagery: mnemonic benefits and theoretical implications. In R. H. Logie \& M. Denis (Eds.), Mental images in human cognition (pp.183-192). North-Holland: Elservier Science Publishers.

McDaniel, M. A., DeLosh, E. L., \& Merritt, P. S. (2000). Order information and retrieval distinctiveness: recall of common versus bizarre material. Journal of Experimental Psychology: Learning, Memory, and Cognition, 26 (4), 1045-1056.

Mercer, C. (1996). The bizarre imagery effect on memory. Journal of Mental Imagery, 20 (3\&4), 141-152.

Merry, R. (1980). Image bizarreness in incidental learning. Psychological Reports, 46 (3), 427-430.

Merry, R., \& Graham, N. C. (1978). Imagery bizarreness in children's recall of sentences. British Journal of Psychology, 69 (3), 315-321.

Michelon, P., Snyder, A. Z., Buckner, R. N., McAvoy, M., \& Zacks, J. M. (2003). Neural correlates of incongruous visual information. An event-related fMRI study. Neurolmage, 19 (7), 1612-1626.

O'Brien, E., \& Wolford, C. L. R. (1982). Effect of delay in testing on retention of plausible versus bizarre mental images. Journal of Experimental Psychology: Human Learning and Memory, 8 (2), 148-152.

Paivio, A. (1986). Mental representation: a dual coding approach. New York: Oxford University Press.

Poon, L. W., \& Walsh-Sweeney, L. (1981). Effects of bizarre and interacting imagery on learning and retrieval of the aged. Experimental Aging Research, 7 (1), 65-70.

Sharpe, L., \& Markham, R. (1992). The effect of the distinctiveness of bizarre imagery on immediate and delayed recall. Journal of Mental Imagery, 16 (3), 211-220.

Sheikh, A. A., \& Sheikh, K. S. (1985). Imagery in education. Farmingdale, NY: Baywood.
Sheikh, A. A., Sheikh, K. S., \& Molesky, L. M. (2002). Techniques to enhance imaging ability. In A. A. Sheikh (Ed.), Therapeutic imagery techniques (pp.383-399). Amityville, NY: Baywood.

Tess, D. E., Hutchinson, R. L., Treloar, J. H., \& Jenkins, C. M. (1999). Bizarre imagery and distinctiveness: Implications for the classroom. Journal of Mental Imagery, 23 (1\&2), 153-170.

Thomas, A. K., \& Loftus, E. F. (2002). Creating bizarre false memories through imagination. Memory \& Cognition, 30 (3), 423-431.

Tulving, E. (1972). Episodic and semantic memory. In E. Tulving \& W. Donalson (Eds.), Organization of memory (pp.381-403). New York: Academic Press.

Tulving, E. (1989). Remembering and knowing the past. American Scientist, 77 (3), 61-367.

Tulving, E. (1993). What is episodic memory? Current Direction in Psychological Science, 2 (1), 67-70.

Wollen, K. A., \& Cox, S. D. (1981). Sentences cuing and the effectiveness of bizarre imagery. Journal of Experimental Psychology: Human, Learning and Memory, 7 (5), 386-392.

Worthen, J. B. (2006). Resolution of discrepant memory strengths: An explanation of the effects of bizarreness on memory. In R. R. Hunt \& J. B. Worthen (Eds.), Distinctiveness and memory (pp.133-156). New York: Oxford Press.

Worthen, J. B., \& Loveland, J. M. (2000-2001). Imagery nonvividness and the mnemonic advantage of bizarreness. Imagination, Cognition and Personality, 20 (4), 373-381.

Worthen, J. B., \& Wood, W. W. (2001). An disruptive effect of bizarreness on memory for relational and contextual details of self-performed and other-performed acts. American Journal of Psychology, 114 (4), 535-546.

Zechmeister, E. B., \& Nyberg, S. E. (1982). Human memory: an introduction to research and theory. Monterey, CA: Brooks/Cole.

Zoler, C. L., Workman, J. S., \& Kroll, N. E. A. (1989). The bizarre mnemonic: the effect of retention interval and mode of presentation. Bulletin of the Psychonomic Society, 27 (3), 215-218.

Recibido el: 5/11/2007

Versión final re-apresentada el: 3/3/2008

Aprobado el: 11/3/2008 